\title{
Research of modification influence on cracking resistance of cast iron in moulds
}

V.A. Gulevskiy, Cand. Eng., Lecturer1, e-mail: gulevskiy.v@mail.ru

S. N. Tsurikhin, Cand. Eng., Associate Prof., Dept. "Machines and technology of foundry production"

V. V. Gulevskiy, Post-graduate student, Dept. "Theoretical mechanics"

N. Yu. Miroshkin, Post-graduate student, Dept. "Machines and technology of foundry production"2

${ }^{1}$ Volgograd Industrial College, Volgograd, Russia

2 Volgograd State Technical University, Volgograd, Russia

\begin{abstract}
The research is devoted to determination of influence of grey iron modification technology; this gray iron is used for manufacture of steel casting moulds. Difficult operating conditions stipulate strict requirements both on construction of moulds and on their materials. These moulds materials should reliably withstand to effect of cast steel with the temperature $1600-1700{ }^{\circ} \mathrm{C}$, as well as to thermal shock which is directly proportional to this temperature, to essential cyclic thermal stresses and deformations. Peculiar operating conditions of moulds (such as high heating temperature, mounting on movable and stationary runners, intensive traffic routes etc.) hamper conduction of the required investigations directly during their operation. The research was carried out on physical models of moulds for consumable electrodes of vacuum arc remelting with geometrical similarity scale 1:10. The following mould models for consumable electrodes, cast of iron, were tested: modified by ferrosilicon FS65 (according to the GOST 1415-93), modified by primary aluminium A99 (according to the GOST 11069-2001), modified by vanadium slag ShVD-1 (according to the technical specification TU 14-11-178-86), modified by ferrosilicobarium FSB-30 and by silicomishmetal SIMISh-1. These modifiers were selected owing to their wide use at production facilities.

Thereby, the conducted tests were aimed to examine the features of moulds walls deformation and stress-strain state on the models of gray and modified cast iron; they allowed to assess the advantages and disadvantages of obtained structure and graphite inclusions forms. They will also help to develop the most rational form of external surface for moulds designed for section and sheet metal, previously determining destruction features. Application of thinwalled moulds with rational form can provide substantial decrease of their specific consumption.

Examination of metal quality which was cast in pilot (lightened) moulds with curved external surface displayed that metal macrostructure for pilot and usual ingots is the same.
\end{abstract}

Key words: gray cast iron, modification, mould, cast iron mould models, bending, thermal stress, deformation.

DOI: $10.17580 /$ cisisr.2021.02.02

\section{Introduction}

The main feature of thermal mould work during its operation is presence of quick cyclically repeated one-side heats induced by liquid steel cast in a mould internal space, as well as consequent cooling processes (including the period after stripping of solidified ingot) [1-4].

A mould wall is subjected to thermal shock during ingot casting and solidification, which is accompanied by its thermal elastic and thermal plastic deformation (buckling). As a result, the high temperature gradient appeared in the mould wall, and essential temperature stresses are arisen; they reach the value of tensile strength of mould material, where gray cast iron is usually used. At the same time, the temperature effect of liquid steel leads to variation in the structure of metallic base, corrosion development, variation of thermal physical and mechanical properties, thermal fatigue of mould cast iron [5-9].

Multiple iterations of very intensive thermal effects on a mould (both on its construction and materials presented by cast iron) are considered as the main causes of its destruction and breakdown. The effect of thermal procedures on a mould can be assessed mostly correct only via joint analytical and experimental approach for solving this problem. Trustworthy description of the temperature field of mould wall is mandatory condition for determining the temperature effect of ingot on a mould; this is the main parameter of temperature stresses and variation of mechanical and thermal physical properties of material [10-12].

Overwhelming majority of the works manufacturing cast iron with spheroidal graphite uses the treatment technology in an open casting ladle with location of modifying additive on its bottom in the special cavity. This cavity is fenced by refractory barrier, and the process itself is known as SandwichVerfahren or "Sandwich process". The methods of liquid cast iron processing are improved gradually [13-17].

Buckling investigation of the moulds for consumable electrodes in the process of vacuum arc remelting was conducted on the cast iron physical models in the form of hollow cylinders with internal diameter $22 \mathrm{~mm}$, external diameter $32 \mathrm{~mm}$ and height $210 \mathrm{~mm}$ (scale 1:10) [18].

It is recognized at present time that computer-aided simulation of complicated tasks about heat exchange and stressed state of materials, dynamics of plastic appearances is often more acceptable than experimental investigations [19-22]. 
However, the authors made the research maximally close to the real working conditions at the enterprise via imitation of heating rate and time of steel casting in a mould. Complicated stress state, appearing during repeating thermal shocks in a mould, initiates the most dangerous dual axial extension in external surface layers during bending of walls. This extension decreases severely the mould construction strength [18].

The aim of this research was to examine influence of different modifiers on bending and cracking resistance of cast iron for moulds, in order to select the rational modifier and to assess the obtained structure and form of graphite inclusions.

\section{Technique of conducting investigations}

Cast iron melting was conducted in the induction furnace IST-006 with capacity $6 \mathrm{~kg}$ and with acidic lining. Cast iron from the "Krasnyi oktyabr" ("Red October") Volgorgad Steel Works" JSC was used as initial charge with the following chemical composition (Table 1).

Metal temperature was kept up to $1440^{\circ} \mathrm{C}$, taking into account two casting operations in a ladle and then in a mould. Temperature control was conducted via electronic automatic potentiometer EPP-09N, using thermocouple VR5/20. As soon as the preset temperature was achieved, metal was tapped in preliminary heated ladle with volume $10 \mathrm{~kg}$. Modifiers were comminuted to fraction $0.5-2.0 \mathrm{~mm}$ and then were added into the ladle. After processing by modifiers, deslagging was conducted and metal was cast in a pilot mould box. The following modifiers were used:

- ferrosilicon FS65 (GOST 1415-93) [8];

- primary aluminium A99 (GOST 11069-2001) [9];

— ferrosilicobarium FSB30 (TY 14-5-160-2006) [10];

- silicomishmetal SIMISh-1 (TУ14-5-24-73) [11];

— vanadium slag ShVD-1 (TY 14-11-178-86) [12].

All above-mentioned modifiers are characterized both be advantages and disadvantages, thereby the analysis of influence of modifying elements on gray cast iron structure was carried out [18].

Heating rate for the sample surface $\left(2^{\circ} / \mathrm{s}\right)$ was maximally approximated to heat loading of internal mould wall, owing to the high heating rate [18].

Relaxation resistance of samples materials was determined after the first cycle; the values of residual stresses, which were appeared during sample casting, were determined. Predisposition of different materials to irreversible deformations, occurring during operation of real moulds, was determined at thermal cycling. Influence of modification on crack resistance of cast iron was examined at the assembly presented on the Fig. 1.

The investigated sample was strictly fixed by its free end between the lower 1 and medium 2 basements, then hanged a loading weight which created stress in the sample: $0.04 ; 0.15$ from $\left[\delta_{\text {ben }}\right]$. The sample was heated up to the temperature $920^{\circ} \mathrm{C}$, with heating rate $8^{\circ} \mathrm{C} / \mathrm{s}$, while maximal temperature gradient across the sample thickness was within $200^{\circ} \mathrm{C}$. The sample deformation was measured using a clock-type indicator 14 with graduation mark $0.01 \mathrm{~mm}$.

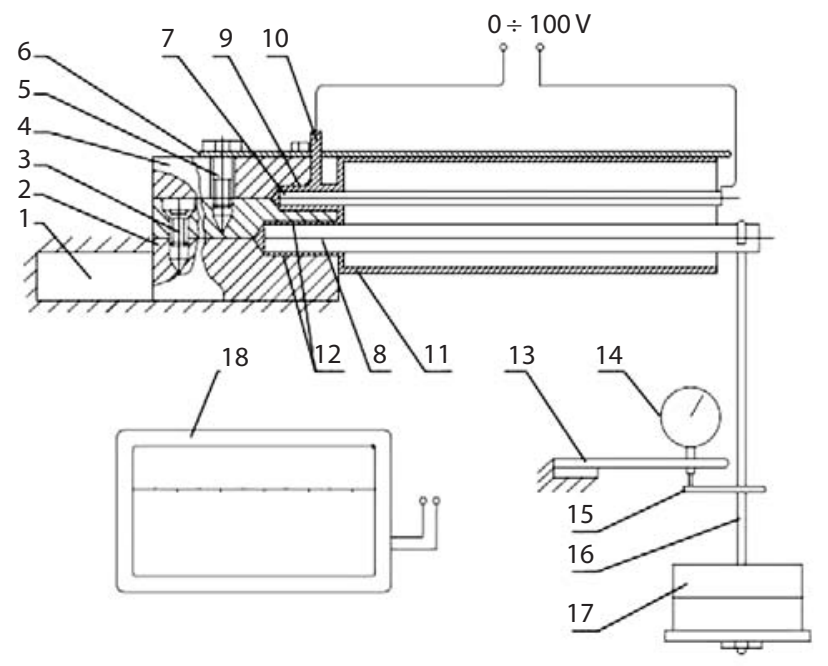

Fig. 1. Assembly for investigation of cast iron crack resistance: 1 - lower basement; 2 - medium basement;

3 - cover; 4 - fixing screws for medium basement;

5 - fixing bolts for cover; 6 - console for screen

fixing; 7 - silicon carbide heater; 8 - tested sample;

9 - current collecting contact;

10 - insulator; 11 - screen;

12 - heat insulation gasket;

13 - plate for indicator fixing; 14 - indicator;

15 - measuring probe; 16 - ram;

$17-$ set of loading weights; $18-$ potentiometer

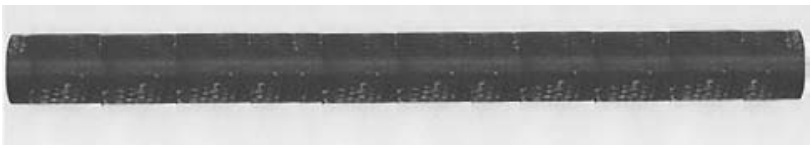

Fig. 2. View of the sample before testing

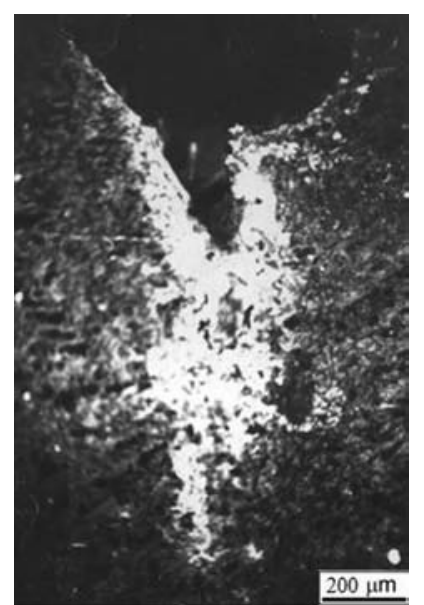

$\boldsymbol{a}$

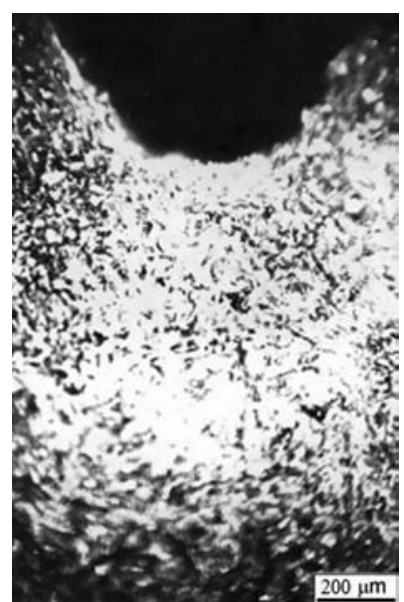

b
Fig 3. View of crack area in the samples of cast iron with lamellar (a) and vermicular (b) graphite form

\begin{tabular}{|c|c|c|c|c|c|}
\hline \multicolumn{5}{|c|}{ Table 1. Chemical composition of initial cast iron } \\
\hline \multirow{2}{*}{ Material } & \multicolumn{5}{|c|}{ Content of the elements, \% } \\
\cline { 2 - 6 } & $\mathrm{C}$ & $\mathrm{Si}$ & $\mathrm{Mn}$ & $\mathrm{S}$ & $\mathrm{P}$ \\
\hline Cast iron & 3.44 & 1.5 & 0.7 & 0.080 & 0.075 \\
\hline
\end{tabular}




\begin{tabular}{|c|c|c|c|c|c|}
\hline \multirow{2}{*}{\multicolumn{3}{|c|}{ Material of sample }} & \multirow[b]{2}{*}{$\begin{array}{c}\sigma_{\text {pilot }} \\
\mathrm{MPa}\end{array}$} & \multicolumn{2}{|c|}{${ }^{*}$ Crack length } \\
\hline & & & & Before thermal & After thermal \\
\hline & & 1 & 2 & 3 & 4 \\
\hline \multirow{6}{*}{ 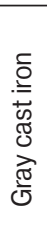 } & & on-modified & 48.135 & 55 & 100 \\
\hline & & vanadium slag & 58.155 & 25 & 32 \\
\hline & $\frac{a}{0}$ & aluminium & 66.10 & 16 & 27 \\
\hline & 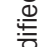 & ferrosilicon & 49.25 & 33 & 56 \\
\hline & $\sum^{0}$ & silicobarium & 64.29 & 0 & 0 \\
\hline & & silicomishmetal & 68.29 & 0 & 0 \\
\hline
\end{tabular}

*the length was measured with magnification $\times 100$

Different values of stresses in the sample were created via making concentrators of various depths. Stress values in the sample with a concentrator were calculated using the following formula:

$$
\delta_{\text {pilot }}=\delta_{\text {calc }} \sqrt{\frac{l}{r}}
$$

where $\delta_{\text {calc }}-$ calculated stress;

$$
\delta_{\text {calc }}=\frac{8 P L}{\pi d^{3}} \text { (GOST 20208-87); }
$$

$l$ - concentrator length; $r$ - radius at concentrator base; $P$ concentrated load at wear moment, $\mathrm{kg} \cdot \mathrm{f} ; L-$ distances between the bearing supports, $\mathrm{mm} ; d$ - sample diameter, $\mathrm{mm}$.

The end of investigated sample was bent up to $2 \mathrm{~mm}$ to create a concentrated crack. To study crack forming and material resistance to crack opening and propagation, polished sections were cut off from the samples. The first party of samples was tested after mechanical processing, and the second party - after thermal cycling. Thermal cycling of the samples for cracking resistance was carried out in the following way: the samples were placed in the furnace with temperature $850^{\circ} \mathrm{C}$, then they were held during $20 \mathrm{~min}$ and subjected to water cooling; cooling after last cycle was conducted in the air. Number of thermal cycles was equal to 30 .

Chemical analysis of initial cast iron is presented in the Table 1, while chemical composition of modifiers and their influence are observed in the work [18]. View of the sample before testing can be seen on the Fig. 2 .

Metallographic examinations were conducted at the microscope OLYMPUS BX51M. The $4 \%$ solution of nitric acid $\mathrm{HNO}_{3}$ in ethyl alcohol $\left(\mathrm{C}_{2} \mathrm{H}_{5} \mathrm{OH}\right)$ was used for pickling of samples in order to find out their actual structure. Graphite inclusions and cast iron structure were assessed according to the GOST 3443-87.

\section{The results of investigation and their discussion}

The results of rests display that the developed technique can serve for assessment of crack forming in gray cast iron which is modified by different additives. Maximal crack length was formed in usual gray cast iron, then follow cast iron modified by aluminium, be vanadium slag, by ferrosilicon.
As for cast iron modified during tests by silicobarium and silicomishmetal, visible cracks were not observed.

Initially the tests were carried out with the load equal to $0.04\left[\sigma_{\text {ben }}\right]$. Bending stress was initiated in the sample fixed on a console in the assembly (see Fig. 1), due to load hanging, while load mass was determined via the formula $\sigma=4 \%\left[\sigma_{\text {ben }}\right]$. The sample was subjected to unilateral heating up to the temperature $920^{\circ} \mathrm{C}$. Deformation of the sample then occurred; it was caused by load effect and it was measured by a clock-type indicator.

Examination of samples for their cracking resistance was started from pilot loadings according to the following scheme: selection of loads set $(Q=10 \mathrm{~kg})$, time of heating and holding ( $\tau=12 \mathrm{~min}$ ), period of data checking is one minute. Maximal temperature of sample heating on the $12^{\text {th }}$ minute was $920^{\circ} \mathrm{C}$, while voltage supplied to autotransformer and silicon carbide heater. Consequently the experiments with the load $15 \mathrm{~kg}$ were conducted according to $12 \mathrm{~min}$ cycle, but the results didn't vary essentially and were similar to those observed with the load $10 \mathrm{~kg}$.

When the load was increased up to $Q=41 \mathrm{~kg}$ and the concentrator with depth $4 \mathrm{~mm}$ is created, destruction of the sample of gray cast iron has occurred during the first cycle. In this case deformation made $8 \mathrm{~mm}$. The large value of deformation does not correspond to the scale of a clock-type indicator. Thereby, the consequent investigations were conducted according to the following cycle: $\left[\sigma_{\text {pilot }}\right]=0.15\left[\sigma_{\text {ben }}\right]$, loading until reaching the ultimate deformation made $2 \mathrm{~mm}$ and the tests after thermal cycling were carried out in the similar way. At the same time cast samples were subjected to thermal cycling in the furnace at the temperature $850^{\circ} \mathrm{C}$, then to holding during $20 \mathrm{~min}$ and to water cooling; but the last cooling was conducted in the air. The results of testing are presented in the Table 2.

We can evaluate the features of stressed state of cast iron in the destruction area via the picture in dark field (Fig. 3). It can be seen there that cast iron with lamellar form of graphite (gray cast iron and cast iron modified by aluminium, ferrosilicon, vanadium slag) have high stress concentration in the researching area, in the section which is parallel to applying load. The samples with vermicular graphite form are characterized by dispersed character of stress distribution in the concentration area (Fig. $3 b$ ).

Graphite inclusions and structure were assessed according to the GOST 3443-87, the results are presented in the Table 3 .

The results of analysis of structure and graphite inclusions in the researched cast iron displayed that introduction of different modifiers provided the following variations of graphite inclusions (unlike with lamellar linear graphite form in gray cast iron): lamellar graphite of whirling form is forming after addition of $\sim 0.8 \%$ of ferrosilicon FS65 or of $1 \%$ of aluminium A99 and vermicular graphite of curved form is forming after addition of vanadium slag $\sim 1.5 \%$ (containing $6 \%$ of vanadium). At the same time, addition of silicobarium FSB30 $1.5 \%$ led to vermicular thickened form of graphite, and addition of silicomishmetal $15 \%$ - to globular compact form of graphite. Thereby addition of modifiers decreases substantially size of graphite inclusions, while graphite amount leads practically the same. 


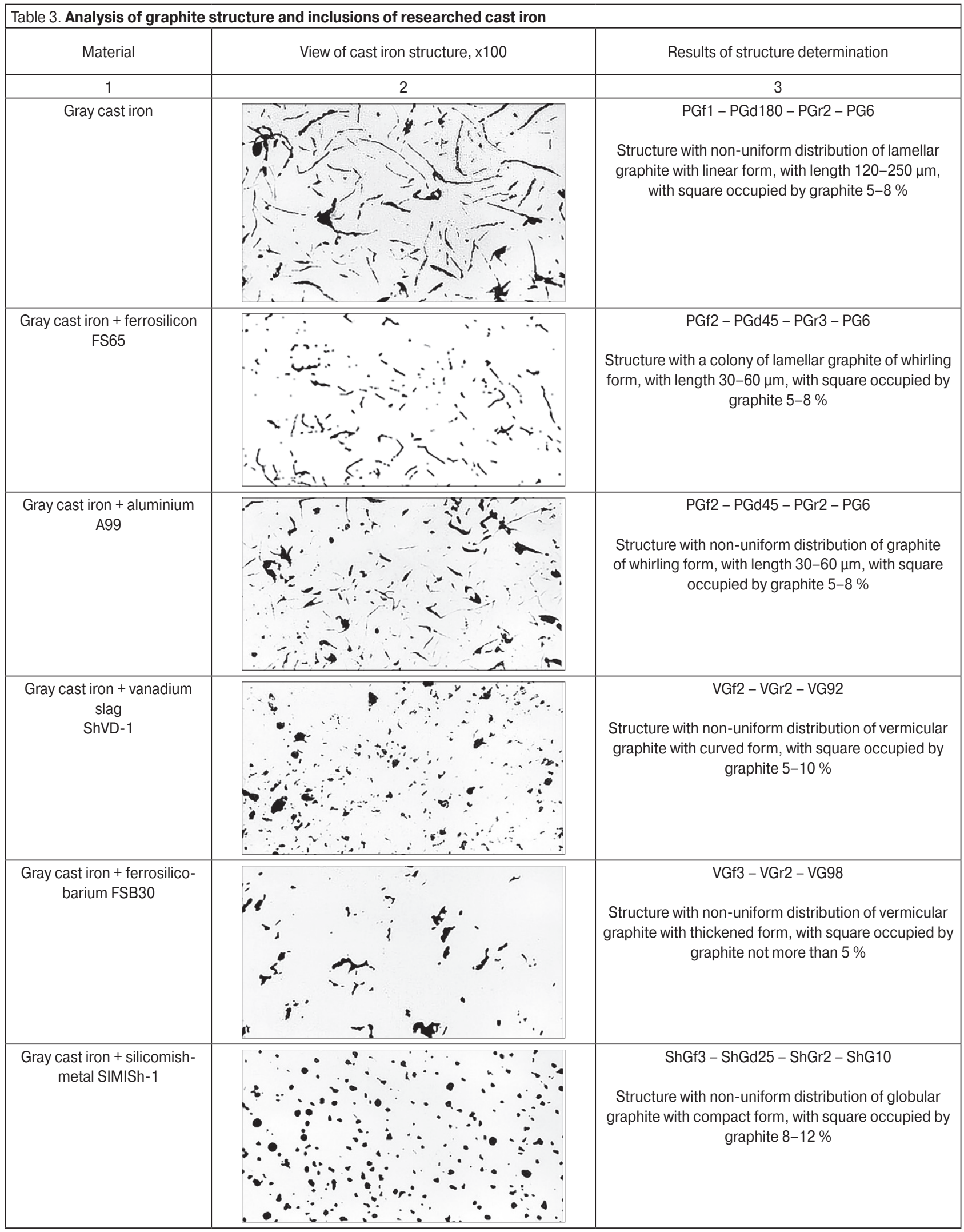

The structure also does not vary (Table 4) in comparison with pearlite structure of usual gray cast iron. Cast iron which is modified by vanadium slag has practically stable pearlite structure, while cast iron modified by ferrosilicon or aluminium are characterized by slight ferritization of a matrix, and cast iron modified by silicobarium and silicomishmetal have significant ferritization of a matrix. Additionally, we can observe variation of pearlite view from lamellar to granular for the samples of cast iron modified by silicobarium and silicomishmetal. 


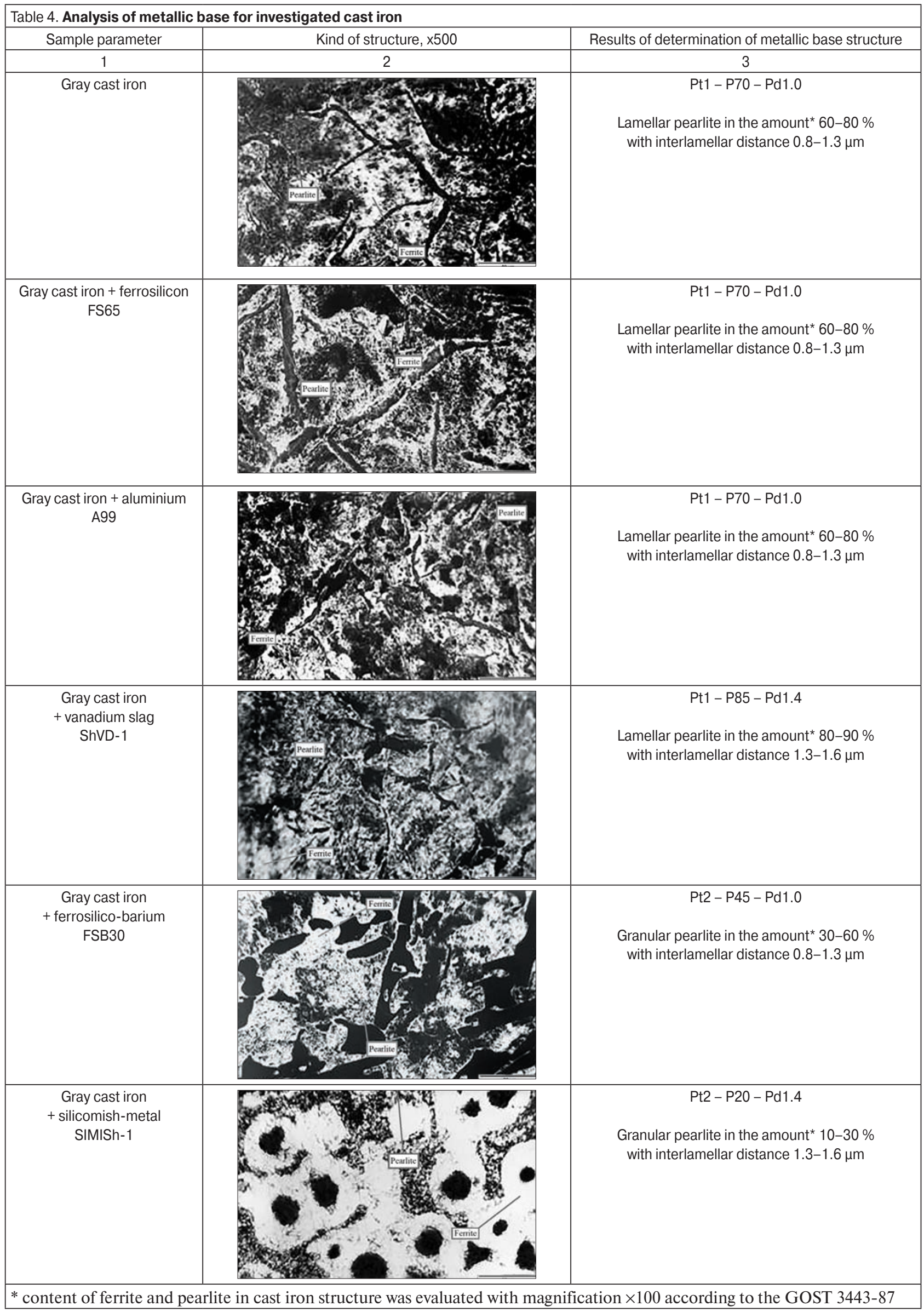




\section{Conclusions}

1. Research of stress-strain state were conducted on the models made of gray and modified cast iron; the bending tests allow to assess advantages and disadvantages of obtained structure and inclusion forms of graphite.

2. Selection of the rational modifier and the method of its introduction are corresponded with the production technology of "Krasnyi oktyabr" corporation" JSC.

3. It is necessary to continue investigations of mould cast iron for buckling and cracking resistance after thermal cycling, using scale models of cast iron and regression analysis and PC calculation.

\section{REFERENCES}

1. Kuksa A. V. Cast iron steel casting moulds. Moscow: Metallurgiya. 1989. $152 \mathrm{p}$.

2. Kostyleva L. V., Ilyinskiy V. A. Gabelchenko N. I., Pozharskiy A. V., Gulevskiy V. A. Investigations of cooling conditions for cast iron castings. Liteinoe proizvodstvo. 1999. No. 2. pp. 9-11.

3. Leushin I. O., Korovin V. A. Relation between modification and graphitization processes in cast iron. Chernye metally. 2010. No. 7. pp. 30-32.

4. Górny M., Tyrała E. Effect of cooling rate on microstructure and mechanical properties of thin-walled ductile iron castings. J. Mater. Eng. Perform. 2013.Vol. 22. Iss.1. pp. 300-305.

5. Vdovin K. N., Gorlenko D. A., Zavalishchin A. N. Study of the effect of isothermal holding on parameters of graphite phase in indefinite chromium-nickel cast iron alloyed by nitrogen and vanadium. CIS Iron and Steel Review. 2019. Vol. 17. pp. 30-33.

6. Tadesse A., Fredriksson H. Volume change during the solidification of grey cast iron: its relation with the microstructural variation, comparison between experimental and theoretical analysis. International Journal of Cast Metals Research. 2017. Vol. 30. No. 3. pp. 159-170.

7. Hong Nga P. T., Ngoc Thien T., Pritadewi P. J., Phuong V. N. Y. Research on Factors Influencing the Formation Graphite and Effect of Graphite on Mechanical Properties of Grey Cast Iron. International Conference on System Science and Engineering (ICSSE) (Dong Hoi, Vietnam.20-21 July 2019). 2019. pp. 619-629.
8. GOST 1415-93 (ISO 5445-80). Ferrosilicon. Technical specifications and delivery conditions (with Variation No. 1). Introduced 01.01.1997.

9. GOST 11069-2001. Primary aluminium. Grades. Introduced 01.01 .2003

10. TU 14-5-321-2010. Complex graphitized modifiers. Introduced 01.01 .2010 .

11. TU 14-5-136-81. Alloying compositions with rare earth metals on ferro-silicon base. Technical specifications. Introduced 01.01.1982.

12. TU 14-11-178-86. Vanadium slag. Technical specifications. Introduced 01.01.1987.

13. Theuwissen K., Lacaze J., Laffont L. Structure of graphite precipitate sin cast iron. Carbon. 2016. Vol. 96. No. 1. pp. 1120-1128.

14. Davydov S. V., Boldyrev D. A., Skantsev V. M. Modifying of graphitized construction cast iron. Bryansk: BGTU. 2015. 113 p.

15. Kidalov N. A., Gabelchenko N. I., Belov A. A., Savchenko A. I. Selection of exothermic carbon-containing additives for regulating of cooling mode of iron castings. Chernye metally. 2020. No. 7. pp. 23-27.

16. Gabelchenko N. I., Belov A. A., Kidalov N. A., Gabelchenko A. I. Improvement of mechanical properties of iron castings via adjusting of solidification rate. CIS Iron and Steel Review. 2020. Vol. 20. pp. 17-20. DOI: 10.17580/cisisr.2020.02.04.

17. Davydov S. V., Boldyrev D. A., Skantsev V. M., Popova L. I. Construction cast irons with compact graphite forms. Vestnik Bryanskogo gosudarstvennogo tekhnicheskogo universiteta. 2015. No. 3. pp. 24-29.

18. Gulevskiy V. A., Tsurikhin S. N., Gulevskiy V. V., Miroshkin N. Yu. Investigation of the modification effect on performance properties of cast iron molds. Chernye metally. 2021. No. 1. pp. 23-28.

19. Monastyrskiy A. V., Smykov A. F., Pankratov V. A., Solovyev M. B. Forecast of hot cracks forming and calculation of buckling in castings at SKMLP "Poligon Soft". Liteinoe proizvodstvo. 2009. No. 10. pp. $27-30$.

20. GOST 7164-78. Automatic sensors for GSP watching equilibration. General technical specifications and delivery conditions (with Variation No. 1, 2, 3). Introduced 01.01.1980.

21. GOST 3443-87. Iron castings with various graphite form. Methods of structure determination. Introduced 01.07.1988.

22. GOST 27208-87/ Iron castings. Methods of mechanical testing. Introduced 01.01.1988. 